\title{
BMJ Open A journey into a Mediterranean diet and type 2 diabetes: a systematic review with meta-analyses
}

\author{
Katherine Esposito, ${ }^{1}$ Maria Ida Maiorino, ${ }^{2}$ Giuseppe Bellastella, ${ }^{2}$ Paolo Chiodini, ${ }^{3}$ \\ Demosthenes Panagiotakos, ${ }^{4}$ Dario Giugliano ${ }^{2}$
}

To cite: Esposito K, Maiorino MI, Bellastella G, et al. A journey into a Mediterranean diet and type 2 diabetes: a systematic review with meta-analyses. BMJ Open 2015;5:e008222. doi:10.1136/bmjopen-2015008222

- Prepublication history and additional material is available. To view please visit the journal (http://dx.doi.org/ 10.1136/bmjopen-2015008222).

Received 18 March 2015 Revised 21 May 2015 Accepted 13 June 2015

For numbered affiliations see end of article.

\section{Correspondence to} Dr Katherine Esposito; Katherine.esposito@unina2.it

\section{ABSTRACT}

Objectives: To summarise the evidence about the efficacy of a Mediterranean diet on the management of type 2 diabetes and prediabetic states.

Design: A systematic review of all meta-analyses and randomised controlled trials (RCTs) that compared the Mediterranean diet with a control diet on the treatment of type 2 diabetes and prediabetic states was conducted. Electronic searches were carried out up to January 2015. Trials were included for meta-analyses if they had a control group treated with another diet, if they were of sufficient duration (at least 6 months), and if they had at least 30 participants in each arm. A random-effect model was used to pool data. Participants: Adults with or at risk for type 2 diabetes.

Interventions: Dietary patterns that described themselves as using a 'Mediterranean' dietary pattern. Outcome measures: The outcomes were glycaemic control, cardiovascular risk factors and remission from the metabolic syndrome.

Results: From 2824 studies, 8 meta-analyses and 5 RCTs were eligible. A 'de novo' meta-analysis of 3 long-term ( $>6$ months) RCTs of the Mediterranean diet and glycaemic control of diabetes favoured the Mediterranean diet as compared with lower fat diets. Another 'de novo' meta-analysis of two long-term RCTs showed a $49 \%$ increased probability of remission from the metabolic syndrome. 5 meta-analyses showed a favourable effect of the Mediterranean diet, as compared with other diets, on body weight, total cholesterol and high-density lipoprotein cholesterol. 2 meta-analyses demonstrated that higher adherence to the Mediterranean diet reduced the risk of future diabetes by $19-23 \%$.

Conclusions: The Mediterranean diet was associated with better glycaemic control and cardiovascular risk factors than control diets, including a lower fat diet, suggesting that it is suitable for the overall management of type 2 diabetes.

\section{INTRODUCTION}

Type 2 diabetes is a global epidemic and a main threat to human health. It is estimated that about 592 million cases worldwide will suffer from type 2 diabetes by the year $2035 .{ }^{1}$ Continued increases in the incidence of diagnosed diabetes, combined with declining

\section{Strengths and limitations of this study}

- It is the first attempt to summarise the evidence about the efficacy of a Mediterranean diet on the management of type 2 diabetes and prediabetic states.

- The statistical power of our attempt is supported by the relevant number of meta-analyses (8) and long-term randomised controlled trials (3). Heterogeneity was low in the primary analysis of a Mediterranean diet and glycaemic control of type 2 diabetes.

- We need more data whether a Mediterranean diet can be translated to other populations and if similar levels of adherence to this eating pattern can be achieved.

- In type 2 diabetes, the use of a Mediterranean diet was associated with lower glycosylated haemoglobin levels and improved cardiovascular risk factors, as compared with control diets, mainly lower fat diets.

mortality, have led to an acceleration of lifetime risk and more years spent with diabetes. $^{2}$ A report ${ }^{3}$ confirmed that diagnosed diabetes is a major factor in total economic costs in the USA, totalling US $\$ 245$ billion in 2012 and accounting for 1 in every 10 healthcare dollars spent. At least US\$147 billion was spent on diabetes healthcare in Europe. ${ }^{1}$ The type 2 diabetes epidemic has been attributed to enhanced accessibility of unhealthy foods and sedentary occupations, ${ }^{4}$ which also favour the occurrence of overweight or obesity. In the affluent Western world regions, as well as in other world regions (Asia, Africa and Latin America), ultraprocessed products have largely replaced food systems and dietary patterns based on fresh and minimally processed food. ${ }^{5}$

Diet is an important factor for the disease burden. Consistent with the state of US Health, 1990-2010, ${ }^{6}$ the aggregate of the 14 subcomponents of diet is a more important factor associated with disease burden than either physical inactivity or high body mass 
index. Worldwide, diets low in fruits rank third for deaths attributable to individual risk factors. ${ }^{4}$ An unhealthy diet has been regarded as a major contributor to the development of type 2 diabetes. Lifestyle interventions, including dietary changes, have a vital role in preventing the progression of impaired fasting glucose (IFG) or impaired glucose tolerance (IGT) to type 2 diabetes in different populations. ${ }^{78}$

Nutrition therapy is an integral component of diabetes prevention, management and self-management education. ${ }^{9}$ The Mediterranean diet is recommended by the American Diabetes Association (ADA) ${ }^{9}$ for its beneficial effects on glycaemic control and cardiovascular risk factors, but only as an alternative to a lower fat, higher carbohydrate eating pattern. The ADA does not recommend any specific diet for prevention of type 2 diabetes. ${ }^{10}$

The aim of this study was to summarise published data on the Mediterranean diet and management of type 2 diabetes and metabolic states at increased risk of future diabetes, including IFG, IGT and metabolic syndrome. We therefore (1) did a systematic review of published meta-analyses of randomised controlled trials (RCTs) that assessed the role of the Mediterranean diet on the management of type 2 diabetes and prediabetic states; (2) did 'de novo' meta-analyses on the same topic including new findings from RCTs and (3) did a convergence analysis of prospective studies and RCTs to assess whether the prevention and management of type 2 diabetes by the Mediterranean diet were concordant.

\section{METHODS}

This study of a systematic review and meta-analysis is in compliance with the guideline PRISMA (Preferred Reporting Items for Systematic reviews and Meta-Analyses).$^{11}$ We carried out this systematic review in accordance with the study protocol (see online supplementary material). A PRISMA statement is attached to follow the reporting of this systematic review.

\section{Search strategy}

A literature search of PubMed, Google Scholar, Cochrane Library and ClinicalTrials.gov was conducted for meta-analyses and RCTs published up to 31 January 2015 which focused on the Mediterranean diet and treatment of type 2 diabetes or prediabetic states. We also included in the search meta-analyses of prospective cohort studies of the Mediterranean diet and prevention of type 2 diabetes. Studies published ahead of print at 31 January 2015 were also included. The main search terms used were 'Mediterranean diet', 'type 2 diabetes', 'prevention of type 2 diabetes', 'prediabetes', 'metabolic syndrome', 'obesity', 'impaired glucose tolerance', 'impaired fasting glucose', 'clinical trials' and 'cardiovascular risk factors'. A full search string for PubMed is reported in the online supplementary material. We identified full-text articles written in English. We also searched the reference lists of identified articles for further papers. Previous reviews and editorials from peer-reviewed journals were used in synthesising data. After the initial screening of titles and abstracts, the studies included by both reviewers were compared; disagreement was resolved by consensus. The inter-review agreement was calculated with $\kappa$ statistics.

\section{Inclusion and exclusion criteria}

We included all meta-analyses focused on the Mediterranean diet and treatment of type 2 diabetes and prediabetic states. We also included RCTs focused on the same topic, if they were not included in previous meta-analyses or if they were to be used for further meta-analyses ('de novo'). We also included all meta-analyses of the Mediterranean diet and prevention of type 2 diabetes. In a conservative approach, trials were included for 'de novo' meta-analyses if they had a control group treated with another diet, if they were of sufficient duration (at least 6 months), if they had at least 30 participants in each arm, and if they described themselves as using a 'Mediterranean' dietary pattern.

\section{Quality assessment}

We assessed the design, execution and reporting of the included RCTs according to the Cochrane risk of bias tool. ${ }^{12}$ We assessed risk of bias in random sequence generation and allocation concealment (selection bias), blinding of participants and personnel (performance bias), blinding of outcome assessment (detection bias), incomplete outcome data (attrition bias) and selective reporting (reporting bias). The risk of bias was deemed high, low and unclear. The quality of each RCT was assessed by one reviewer and verified by another reviewer. Disagreement was resolved by discussion. The quality of the body of evidence of each meta-analysis was assessed by the GRADE approach. ${ }^{13}$ Each evaluated factor was rated as high, moderate, low or very low. A serious risk of bias was defined as present when an individual study had more than three unclear or high risks of bias, and imprecision was defined as a meta-analysis $\mathrm{CI}>0.5$.

\section{Convergence analysis}

We did a convergence analysis to see whether the Mediterranean diet could affect the prevention and management of type 2 diabetes in a similar way. In a conservative approach, we graded the level of evidence as good when the results of both prospective studies on diabetes prevention and RCTs on glycaemic control of diabetes were both positive (the Mediterranean diet can not only reduce the incidence of future diabetes, but also improve the glycaemic control of type 2 diabetes better than control diets).

\section{Data analysis}

We summarised the results of previous meta-analyses with the Mediterranean diet. We did 'de novo' 
meta-analyses of RCTs with the Mediterranean diet according to inclusion criteria: one meta-analysis assessed changes in glycosylated haemoglobin (HbA1c) in type 2 diabetes, and another assessed the probability of remission from the metabolic syndrome. Regardless of whether a trial presented two arms of the Mediterranean diet compared to one control diet, we preliminary pooled data from the two interventional arms with a Mediterranean diet in order to avoid distortion of the $95 \%$ coefficient intervals of the final estimate. In a conservative approach, the random-effects model, which allows for variation of true effects across studies, was taken as 'main results'. ${ }^{14}$ Heterogeneity was assessed by using the $Q$ statistic and $\mathrm{I}^{2}$, which is the proportion of total variance observed between the trials attributed to the differences between trials rather than to sampling error. ${ }^{15} \mathrm{I}^{2}<25 \%$ was considered as low in heterogeneity and $\mathrm{I}^{2}>75 \%$ as high in heterogeneity. Possible publication bias was assessed using a contourenhanced funnel plot of each trial's effect size against the SE. Funnel plot asymmetry was evaluated by Begg and Egger tests. All statistical analyses were performed using Stata V.11.0 software (Stata, College Station, Texas, USA). Significance was set at $\mathrm{p}<0.05$, and $95 \%$ CIs are quoted throughout.

\section{RESULTS}

We identified 2824 studies in database searches (figure 1). Of these, 2680 were excluded based on the title and abstract, leaving 144 articles for further full text evaluation. One hundred and thirty of these studies were excluded, most of them focusing on components of the Mediterranean diet only, RCTs not in agreement with inclusion criteria or already covered by published meta-analyses. Therefore, eight meta-analyses ${ }^{16-23}$ and five $\mathrm{RCTs}^{2-28}$ were eligible. Agreement between observers on which studies to include was good: the к scores for agreement between the two reviewers were $86 \%$ after screening titles and abstracts, and approached 100\% after screening full-text articles.

\section{Study characteristics}

The characteristics of the eight included meta-analyses and the five RCTs are summarised in table 1. The meta-analyses were published from 2011 to 2014, with half of them published in 2014. Six meta-analyses ${ }^{16-21}$ reported RCTs of the Mediterranean diet as compared with other diets, and considered as outcomes HbAlc, body weight, total cholesterol and high-density lipoprotein (HDL) cholesterol; three of these meta-analyses $^{18} \quad 20 \quad 21$ included RCTs performed on patients with type 2 diabetes only, and the other three $^{16} \quad 17 \quad 19$ included RCTs performed on a mixed population. Two meta-analyses ${ }^{22} 23$ included mostly prospective cohort studies on adherence to the Mediterranean diet and incidence of future diabetes. Two RCTs ${ }^{24} 25$ specifically investigated the effect of the
Mediterranean diet, as compared with a control diet, on the remission from metabolic syndrome in people with or without type 2 diabetes at baseline; the other three $\mathrm{RCTs}^{26-28}$ assessed the effect of the Mediterranean diet on glycaemic control of diabetes. All the RCTs satisfied the strict inclusion criteria. Besides evaluating remission of metabolic syndrome by the Mediterranean diet, ${ }^{25}$ the PREDIMED trial also assessed the effect of two Mediterranean diets on diabetes incidence. ${ }^{29}$ We did not find any RCT that specifically addressed the effect of the Mediterranean diet in people with either IGT or IFG that satisfied the inclusion criteria.

\section{Risk of bias}

The individual quality of the five RCTs revealed a low risk of bias for most evaluated domains, except for blinding of participants and personnel, which, owing to the inherent characteristics of the dietary studies, was marked as unclear (see online supplementary figure S1). Most RCTs described some type of assessment of diet compliance. The GRADE quality of evidence was mostly moderate for the meta-analyses (see online supplementary table S1).

\section{Glycaemic control of diabetes}

We did a meta-analysis of long-term clinical trials of the Mediterranean diet and glycaemic control in type 2 diabetes (figure 2, top panel). We found three interventional trials, ${ }^{26-28}$ with four arms, as Elhayany et $a l^{27}$ compared two different Mediterranean diets with the same control diet. The results show an overall effect estimate for HbAlc of $-0.47 \% \quad(95 \%$ CI -0.56 to -0.38$)$ favouring the Mediterranean diet, as compared with the usual care ${ }^{26}$ or a low-fat diet, ${ }^{27} 28$ with no heterogeneity $\left(\mathrm{I}^{2}=3.5 \%\right)$. The Egger tests were not calculated due to the small number of included studies. Figure 3 (top panel) shows a summary of the four meta-analyses ${ }^{182021}$ (+ that reported in figure 2 ) of the Mediterranean diet and glycaemic control in type 2 diabetes. All the four analyses favour the Mediterranean diet, with a greater $\mathrm{HbA1c}$ reduction, ranging from $-0.3 \%$ to $-0.47 \%$, as compared with the control diet. The absence of heterogeneity in the meta-analysis of figure 2 (top panel), as compared with other meta-analyses in figure 3 (top panel), may be related to the strict entry criteria we adopted for selecting RCTs.

\section{Cardiovascular risk factors}

Five meta-analyses ${ }^{16-20}$ included RCTs which assessed cardiovascular risk factors. In The Cochran review of Rees $e t a l,{ }^{19}$ seven RCTs described the intervention as a Mediterranean diet, and only four RCTs provided sufficient data on cholesterol levels for being meta-analysed. Heterogeneity precluded meta-analyses for other outcomes. The meta-analyses of Nordmann et $a l^{17}$ and Esposito et $a l^{16}$ included RCTs comparing the Mediterranean diet with low-fat diets in overweight/ obese individuals, including patients with type 2 diabetes. Three meta-analyses ${ }^{17} 1920$ reported the effect on 


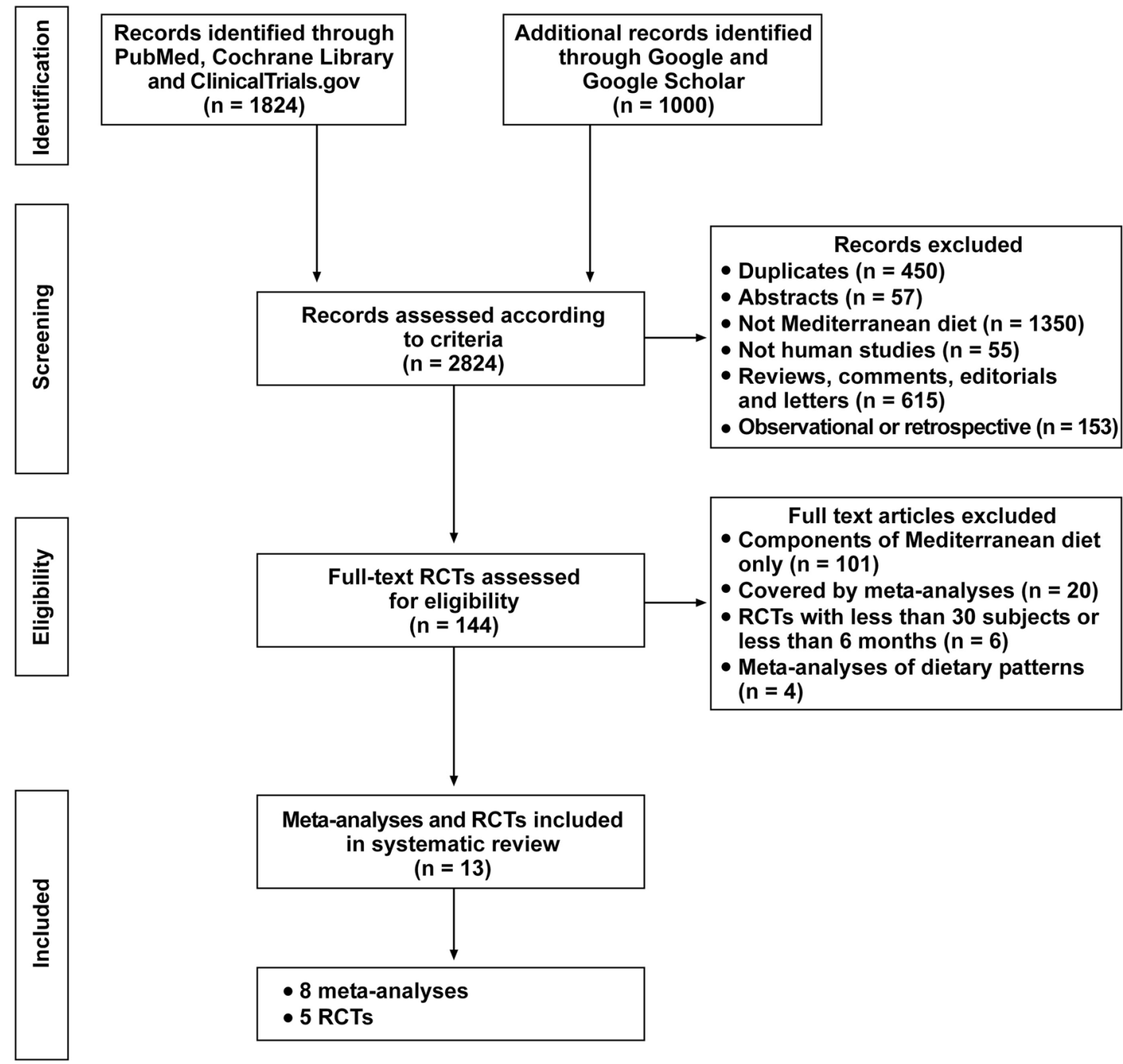

Figure 1 Flow diagram of literature search to identify meta-analyses and randomised controlled trial evaluating the effect of Mediterranean diet in type 2 diabetes and prediabetic states.

total cholesterol (figure 3, middle panel): the reduction in total cholesterol was statistically significant with the Mediterranean diet as compared with control diets, and ranged from $-5.4^{20}$ to $-8.9 \mathrm{mg} / \mathrm{dL}{ }^{19}$ Two of these meta-analyses $^{19} \quad 20$ had low heterogeneity. Four meta-analyses ${ }^{16-18}{ }^{20}$ reported the effect on body weight. Figure 3 (bottom panel) shows that all meta-analyses found a significant reduction in body weight with the Mediterranean diet, as compared with control diets, ranging from $-0.29^{20}$ to $-2.2 \mathrm{~kg} ;{ }^{17}$ heterogeneity was low in the meta-analysis of Huo et $a l^{20}$ Two meta-analyses ${ }^{18} 20$ also found a significant increase in HDL cholesterol with the Mediterranean diet, as compared with control diets (table 1).

\section{Metabolic syndrome}

Two RCTs ${ }^{24}{ }^{25}$ specifically evaluated the relationship between a Mediterranean diet and metabolic syndrome regression. The results (figure 2, lower panel) indicate that participants with the metabolic syndrome allocated to a Mediterranean diet, as compared with those following a control diet, had a $49 \%$ (95\% CI $14 \%$ to $96 \%$ ) increased probability of remission from metabolic syndrome during a follow-up of 2-5 years.

\section{Prevention of diabetes}

Two meta-analyses ${ }^{22} 23$ assessed the relationship between adherence to a Mediterranean diet and incidence of future diabetes. The analyses are consistent with a significant reduction, ranging from $19 \%$ to $23 \%$, of new diabetes associated with greater adherence to the Mediterranean diet (table 1). So far, only one long-term RCT $^{29}$ provided evidence that a Mediterranean diet reduced the development of type 2 diabetes.

\section{Convergence analysis}

The convergence analysis was positive that: (1) a Mediterranean diet can prevent type 2 diabetes (evidence from 2 meta-analyses of prospective cohort studies and 1 long-term RCT) and (2) a Mediterranean diet is better than a control diet in reducing HbAlc levels in type 2 diabetes (evidence from 4 meta-analyses of RCTs). 
Table 1 Characteristics of meta-analyses and RCTs included in the review

\begin{tabular}{|c|c|c|c|c|c|c|}
\hline $\begin{array}{l}\text { Authors, year and } \\
\text { reference }\end{array}$ & $\begin{array}{l}\text { Design } \\
\text { (meta-analysis or RCT) }\end{array}$ & Evaluation & Population & Outcome & $\begin{array}{l}\text { Quality } \\
\text { (meta-analyses), } \\
\text { risk of bias (RCT) }\end{array}$ & Results $(95 \% \mathrm{Cl})$ \\
\hline Esposito et al, $2011^{16}$ & Meta-analysis (15 RCTs) & Body weight $(\mathrm{kg})$ & $\begin{array}{l}\text { Obese and/or type } 2 \\
\text { diabetes }\end{array}$ & Mean difference & Moderate & $-1.75(-2.86$ to -0.64$)$ \\
\hline Nordmann et al, $2011^{17}$ & Meta-analysis (6 RCTs) & $\begin{array}{l}\text { Body weight }(\mathrm{kg}) \\
\text { Cholesterol }(\mathrm{mg} / \mathrm{dL})\end{array}$ & Mixed & $\begin{array}{l}\text { Mean difference } \\
\text { Mean difference }\end{array}$ & Moderate & $\begin{array}{l}-2.2(-3.9 \text { to }-0.6) \\
-7.4(-10.3 \text { to }-4.4)\end{array}$ \\
\hline Ajala et al, $2013^{18}$ & Meta-analysis (3 RCTs) & $\begin{array}{l}\text { Body weight }(\mathrm{kg}) \\
\text { HbA1c }(\%) \\
\text { HDL-C (mg/dL) }\end{array}$ & Type 2 diabetes & $\begin{array}{l}\text { Mean difference } \\
\text { Mean difference } \\
\text { Mean difference }\end{array}$ & Moderate & $\begin{array}{l}-1.84(-2.54 \text { to }-1.15) \\
-0.41(-0.58 \text { to }-0.24) \\
1.54(0.38 \text { to } 2.71)\end{array}$ \\
\hline Rees et al, $2013^{19}$ & Meta-analysis (4 RCTs) & Cholesterol (mg/dL) & Mixed & Mean difference & Moderate/high & $-8.9(-10.4$ to -7.7$)$ \\
\hline Huo et al, $2014^{20}$ & Meta-analysis (11 RCTs) & $\begin{array}{l}\text { Body weight }(\mathrm{kg}) \\
\text { HbA1c } \\
\text { Cholesterol }(\mathrm{mg} / \mathrm{dL}) \\
\text { HDL-C (mg/dL) }\end{array}$ & Type 2 diabetes & $\begin{array}{l}\text { Mean difference } \\
\text { Mean difference } \\
\text { Mean difference } \\
\text { Mean difference }\end{array}$ & Moderate & $\begin{array}{c}-0.29(-0.55 \text { to }-0.04) \\
-0.30(-0.61 \text { to }-0.38) \\
-5.4(-7.3 \text { to }-3.5) \\
2.31(0.77 \text { to } 3.86)\end{array}$ \\
\hline Carter et al, $2014^{21}$ & Meta-analysis (3 RCTs) & $\mathrm{HbA} 1 \mathrm{c}(\%)$ & Type 2 diabetes & Mean difference & Low/moderate & $-0.30(-0.61$ to -0.03$)$ \\
\hline Koloverou et al, $2014^{22}$ & $\begin{array}{l}\text { Meta-analysis (1 RCT, } 9 \\
\text { cohorts) }\end{array}$ & $\begin{array}{l}\text { Incidence of } \\
\text { diabetes }\end{array}$ & $\begin{array}{l}\text { Without diabetes at } \\
\text { baseline }\end{array}$ & Relative risk & Moderate & 0.77 (0.66 to 0.89$)$ \\
\hline $\begin{array}{l}\text { Schwingshackl et al, } \\
2015^{23}\end{array}$ & $\begin{array}{l}\text { Meta-analysis (1 RCT, } 8 \\
\text { cohorts) }\end{array}$ & $\begin{array}{l}\text { Incidence of } \\
\text { diabetes }\end{array}$ & $\begin{array}{l}\text { Without diabetes at } \\
\text { baseline }\end{array}$ & Relative risk & Moderate & $0.81(0.73$ to 0.90$)$ \\
\hline Esposito et al, $2004^{24}$ & $\mathrm{RCT}$ & Remission from MS & People with MS & HR & Low & 1.74 (1.36 to 2.21$)$ \\
\hline Babio et al, $2014^{25}$ & $\mathrm{RCT}^{*}$ & Remission from MS & People with MS & $\mathrm{HR}$ & Low & $1.32(1.12$ to 1.55$)$ \\
\hline Toobert et al, $2003^{26}$ & $\mathrm{RCT}$ & $\mathrm{HbA} 1 \mathrm{c}(\%)$ & Type 2 diabetes & Mean difference & Unclear & $-0.34(-0.67$ to -0.01$)$ \\
\hline Elhayany et al, $2010^{27}$ & $\mathrm{RCT}$ & HbA1c (\%) & Type 2 diabetes & Mean difference & Low & $-0.28(-0.63$ to -0.07$)$ \\
\hline Esposito et al, $2014^{28}$ & $\mathrm{RCT}$ & $\mathrm{HbA} 1 \mathrm{c}(\%)$ & Type 2 diabetes & Mean difference & Low & $-0.50(-0.60$ to -0.40$)$ \\
\hline $\begin{array}{l}\text { Salas-Salvadò et al, } \\
2014^{29}\end{array}$ & $\mathrm{RCT}^{*}$ & $\begin{array}{l}\text { Incidence of } \\
\text { diabetes }\end{array}$ & $\begin{array}{l}\text { People without } \\
\text { diabetes }\end{array}$ & $\mathrm{HR}$ & Low & $0.60(0.43$ to 0.85$) \dagger$ \\
\hline & & & & & & $0.82(0.61$ to 1.10$) \ddagger$ \\
\hline
\end{tabular}

*Same RCT with two different outcomes.

†Mediterranean diet supplemented with extra virgin olive oil.

¥Mediterranean diet supplemented with nuts.

Cholesterol, total cholesterol; HbA1c, glycosylated haemoglobin; HDL-C, high-density lipoprotein cholesterol; MS, metabolic syndrome; RCT, randomised controlled trial. 
Figure 2 Meta-analysis of three long-term RCTs of Mediterranean diet and glycaemic control of diabetes (top panel). The two arms in the RCT by Elhayany were preliminary pooled. Meta-analysis of metabolic syndrome regression by Mediterranean diet (bottom panel). The two arms in the RCT by Babio were preliminary pooled (HbA1c, glycosylated haemoglobin; RCT, randomised controlled trial).

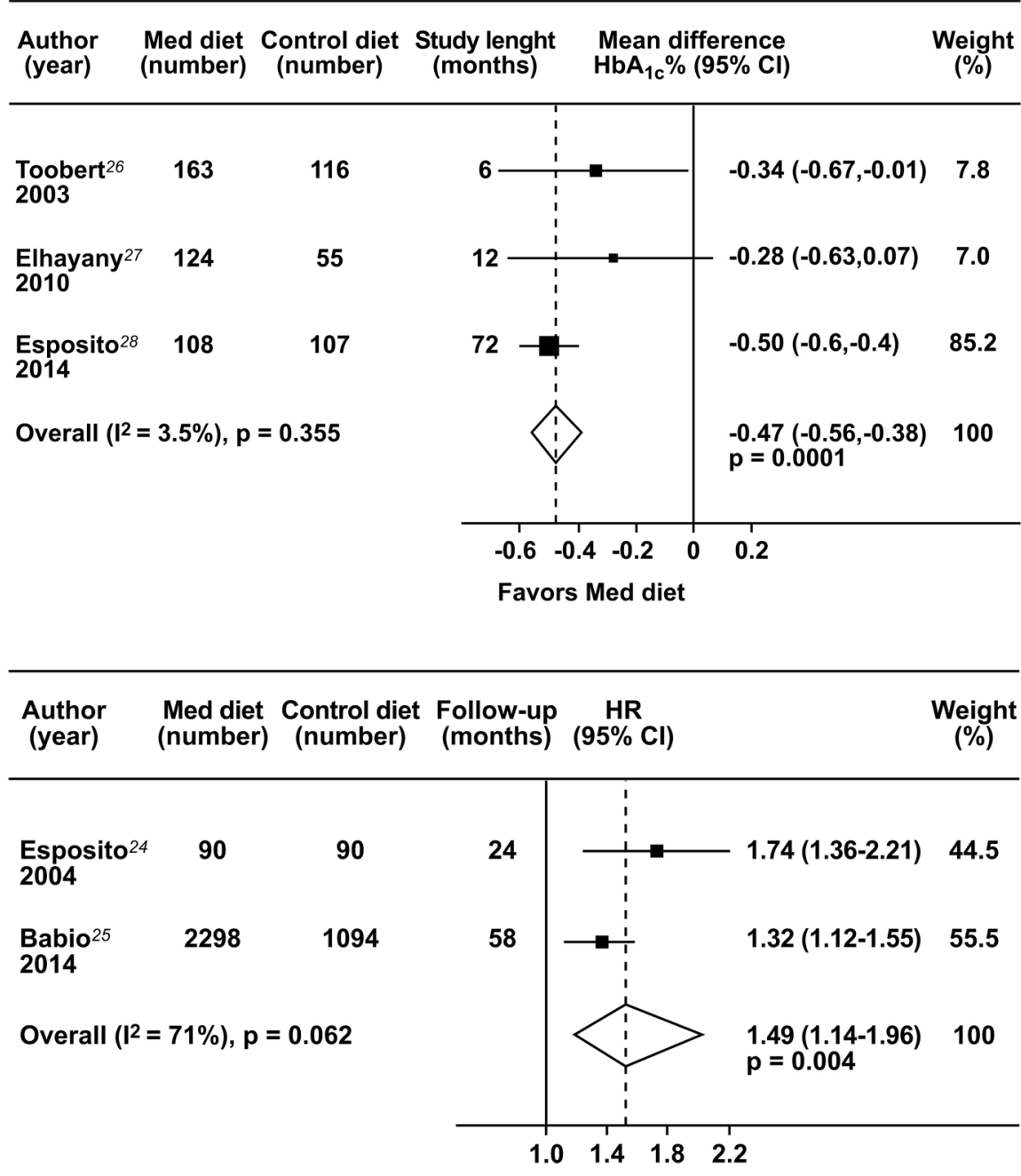

\section{DISCUSSION}

Traditionally, dietary recommendations have targeted macronutrient levels. However, recent dietary guidelines ${ }^{30}$ have shifted towards a more food-based dietary pattern approach. Although several macronutrients, micronutrients and individual foods have been associated with diabetes risk, assessment of dietary patterns is increasingly used as an alternative method to traditional single nutrient analysis because it can assess cumulative effects of the overall diet. ${ }^{31}$

Current evidence indicates that the Mediterranean diet is effective in improving both glycaemic control and cardiovascular risk factors in people with type 2 diabetes, and should therefore be considered in the overall strategy for management of people with diabetes. The convergence analysis of prospective studies and interventional trials was satisfied: the Mediterranean diet is able to reduce the incidence of future diabetes by 19-23\%. A significant reduction of type 2 diabetes has been found to be associated with greater consumption of healthy dietary patterns, including the Mediterranean diet, the DASH (Dietary Approach to Stop Hypertension) diet, the AHEI (Alternative Healthy Eating Index) and various a posteriori defined prudent/ healthy dietary patterns, derived by factor or cluster analysis. ${ }^{32}$ All the protective dietary patterns, including the vegetarian diet, ${ }^{33}$ present many similarities with the Mediterranean diet, since they are mostly plant-based and include a high consumption of whole-grain foods, fruit and vegetables. In the PREDIMED trial, ${ }^{29} 3541$ patients without diabetes at high cardiovascular risk were randomly assigned to education on either a low-fat diet or to one of two Mediterranean diets, supplemented with either free virgin olive oil $(1 \mathrm{~L} /$ week $)$ or nuts (30 g/day). After a 4.1-year follow-up, participants assigned to the two Mediterranean diets without calorie restriction had a $40 \%$ (significant) and $18 \%$ (nonsignificant) reduction, respectively, in the risk of diabetes compared with a low-fat control diet.

All meta-analyses so far published, including the one presented here in figure 2 (top panel), are concordant and indicate that the Mediterranean diet, as compared with control diets, may reduce $\mathrm{HbA1c}$ levels by 0.30 $0.47 \%$, which is not banal in the overall management of type 2 diabetes. Although not satisfying the inclusion criteria $(<30$ patients for each arm), the study of Shai et $a l^{34}$ also showed a HbAlc reduction of $0.5 \pm 1.1 \%$ among obese participants with diabetes at 24 months. 
Figure 3 Summary of meta-analyses of Mediterranean diet and $\mathrm{HbA1c}$ (top panel), total cholesterol (middle panel) and body weight (bottom panel). *This meta-analysis refers to figure 2 (top panel; HbA1c, glycosylated haemoglobin; RCT, randomised controlled trial).

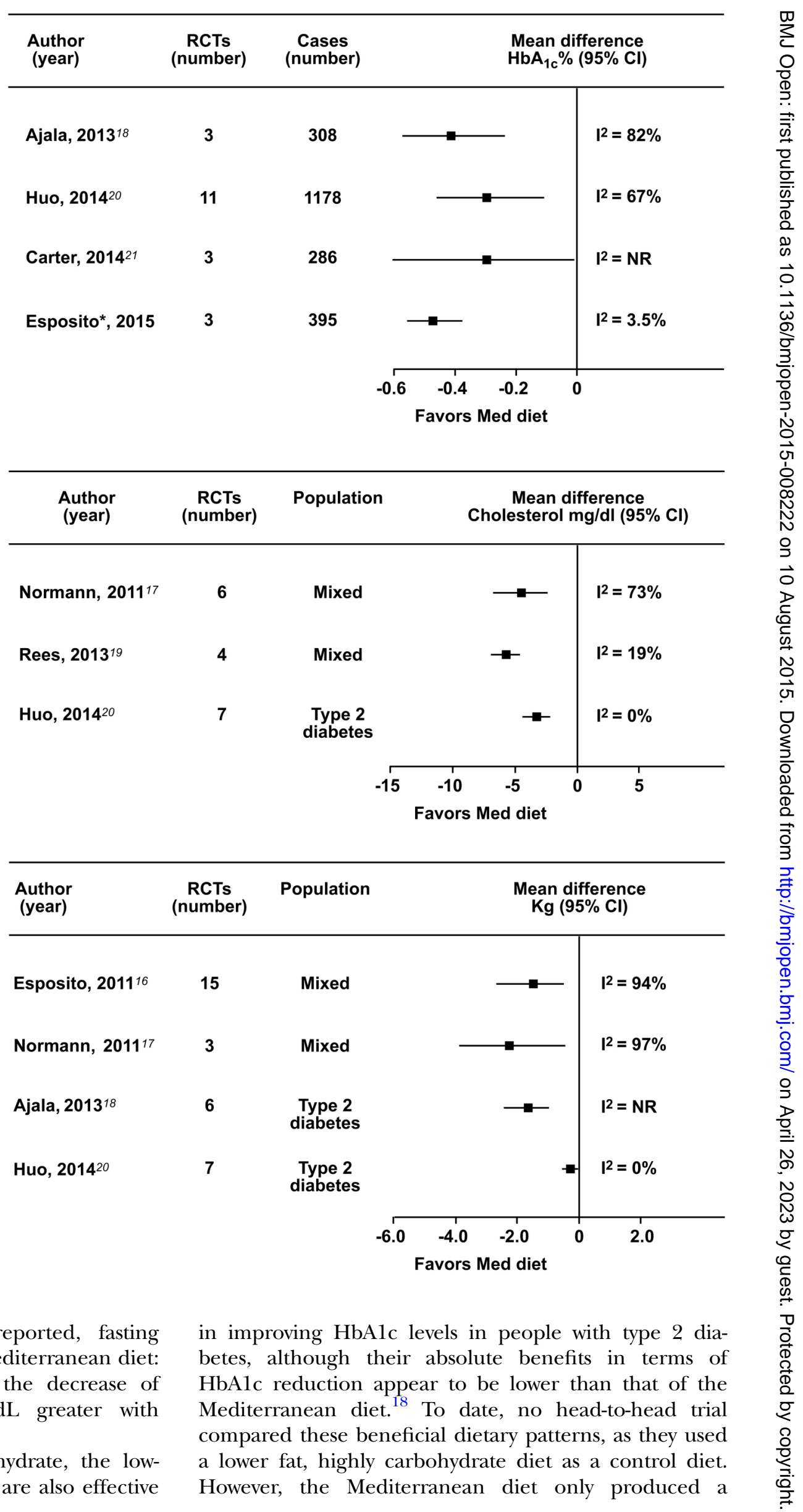


favourable effect on cardiovascular risk factors. ${ }^{18} 20$ The relatively high content of fat (up to 40\%) in the Mediterranean diet might be a topic of concern, partly due to the possible effect on weight gain. However, no significant association has been found between the amount or type of dietary fat and subsequent weight change in large prospective studies; ${ }^{35} 36$ moreover, no RCT included in the largest meta-analysis so far published $^{16}$ reported increased weight gain with the Mediterranean diet, as compared with the control diet, despite the fact that the intake of monounsaturated fatty acids may be so high as to cover about one-quarter of the daily caloric intake. ${ }^{37}$

The Mediterranean diet also improved the lipid arm of the cardiovascular risk, as it reduced total cholesterol and increased HDL cholesterol levels, which may help in the management of patients at high cardiovascular risk, as the patient with diabetes undoubtedly is. A systematic review ranked the Mediterranean diet as the most likely dietary pattern to provide protection against coronary heart disease. ${ }^{38}$ The results of the PREDIMD study, ${ }^{39}$ which included 3614 participants with type 2 diabetes, showed a $30 \%$ and a $28 \%$ reduced risk for cardiovascular events (myocardial infarction, stroke or death from cardiovascular causes) for participants assigned to a Mediterranean diet supplemented with olive oil and a Mediterranean supplemented with nuts, respectively, compared with the low-fat diet control group, after a median follow-up of 4.8 years. In the longest interventional trial of the Mediterranean diet in newly-diagnosed patients with type 2 diabetes to date, with a follow-up of 8 years, ${ }^{28}$ the rate of regression in the intima-media thickness of the carotid artery was higher $(49 \%)$ and the rate of progression lower $(25 \%)$ in the Mediterranean diet group as compared with the low-fat diet group ( $26 \%$ and $50 \%$, respectively). ${ }^{41}$

The metabolic syndrome can be considered a prediabetic state. ${ }^{42}{ }^{43}$ Current evidence from RCTs indicates that the Mediterranean diet confers a $49 \%$ increased probability of remission from metabolic syndrome in a long-term follow-up. Three prospective studies ${ }^{44-46}$ evaluated the role of the Mediterranean diet in the prevention of metabolic syndrome and found that higher adherence to the Mediterranean diet was associated with reduced risk of developing metabolic syndrome ranging from $15 \%{ }^{45}$ to $80 \% .{ }^{44}$ However, one large clinical trial ${ }^{25}$ failed to find an association between the Mediterranean diet and incident metabolic syndrome.

The potential protection from diabetes by the Mediterranean diet may be considered as antiinflammatory and antioxidative, principally because of the increased intake of protective nutrients such as dietary fibre, vitamins and minerals, as well as antioxidants and polyphenols, whereas they are also characterised by a lower intake of proinflammatory aliments and nutrients, such as saturated and trans fatty acids, refined sugars and starches and generally foods that account for excess energy intake. ${ }^{47}$ Supporting this line of thought, a recent meta-analysis of prospective studies identified two inflammatory markers, that is, interleukin 6 and $\mathrm{C}$ reactive protein, significantly associated with diabetes, with an increased risk of $26 \%$ for elevated $\mathrm{C}$ reactive protein and $31 \%$ for elevated interleukin 6 levels. $^{48}$ The Mediterranean diet has been the first dietary pattern associated with significant reductions of both proinflammatory cytokine levels in a clinical trial, ${ }^{24}$ a finding confirmed by a meta-analysis of 17 trials with 2300 patients. $^{49}$

This review has limitations. One limitation relates to the low number of original trials of long duration on the Mediterranean diet and diabetes control. However, all three trials ${ }^{26-28}$ so far published show similar results with no heterogeneity, giving support to the robustness of the findings, and in part balancing the possibility of low statistical power of meta-analysis including a limited number of trials. Moreover, consistency across these studies on the definition of the Mediterranean diet varies, including the use of olive oil as the main source of dietary fat. However, the results all show a reduction of HbAlc with the Mediterranean diet, as compared with control diets, suggesting that similarities across different definitions of the Mediterranean diet prevail on marginal differences. Moreover, some meta-analyses, ${ }^{19}$ although judged to be of moderate/good quality by current GRADE testing, may be biased by the exclusion of some relevant studies. Another possible limitation of this review includes the need to find the optimal strategies for educating individuals with type 2 diabetes and to improve adherence to the Mediterranean diet. Living in a neighbourhood rich in resources for physical activity and healthful foods compared with living in an environment not encouraging a healthy lifestyle is associated with a $38 \%$ lower incidence of type 2 diabetes. ${ }^{50}$ Further research is also needed to determine if the study results with the Mediterranean diet can be translated to other populations and if similar levels of adherence to this eating pattern can be achieved. A further issue relates to the macronutrient composition of the Mediterranean diet. A carbohydrate content of less than $50 \%$ of daily energy is associated with benefits on diabetes incidence, ${ }^{29}$ glycaemic control of diabetes, ${ }^{27} 28$ and cardiovascular outcomes ${ }^{39}$ in RCTs. A reduced carbohydrate content also fits with the abundant use of monounsaturated fat (about 20\%), mainly olive oil, used in the trials with a Mediterranean diet. At present, the Mediterranean diet with a moderately lower carbohydrate content best fits with the results of RCTs in individuals with or at risk for type 2 diabetes. Lastly, despite country-specific variations in the foods consumed, which have also changed over time, there are commonalities in food groups and their frequency of consumption that characterise the Mediterranean diet (see online supplementary table S2).

In conclusion, in patients with type 2 diabetes, the use of the Mediterranean diet was associated with lower HbA1c levels and improved cardiovascular risk factors, 
as compared with control diets, mainly lower fat diets. The present available evidence suggests that the Mediterranean diet is a dietary pattern suitable for the overall management of type 2 diabetes. Unesco inscribed the Mediterranean diet in 2010 and again in 2013 on the list of the Intangible Cultural Heritage of Humanity (http://www.unesco.org/culture/ich/index. php?lg=en\&pg $=00011 \&$ RL $=00884)$.

\section{Author affiliations}

${ }^{1}$ Diabetes Unit, Department of Clinical and Experimental Medicine, Second University of Naples, Naples, Italy

2Division of Endocrinology and Metabolic Diseases, Department of Medical, Surgical, Neurological, Metabolic Sciences and Aging, Second University of Naples, Naples, Italy

${ }^{3}$ Medical Statistics Unit, Second University of Naples, Naples, Italy

${ }^{4}$ Department of Nutrition and Dietetics, Harokopio University, Athens, Greece

Contributors KE and DG designed the protocol and the methods. PC and DG carried out the statistical analyses. All the authors contributed to data extraction, drafting of the article and approved the final version of the manuscript.

Funding This study was funded in part with support from the Second University of Naples and the 'Salute con Stile' Association.

Competing interests None declared.

Patient consent Obtained.

Provenance and peer review Not commissioned; externally peer reviewed.

Data sharing statement No additional data are available.

Open Access This is an Open Access article distributed in accordance with the Creative Commons Attribution Non Commercial (CC BY-NC 4.0) license, which permits others to distribute, remix, adapt, build upon this work noncommercially, and license their derivative works on different terms, provided the original work is properly cited and the use is non-commercial. See: http:// creativecommons.org/licenses/by-nc/4.0/

\section{REFERENCES}

1. International Diabetes Federation. IDF diabetes atlas (6th edn.) 2013. http://www.idf.org/diabetesatlas (accessed 10 Feb 2015).

2. Gregg EW, Zhuo X, Cheng YJ, et al. Trends in lifetime risk and years of life lost due to diabetes in the USA, 1985-2011: a modelling study. Lancet Diabetes Endocrinol 2014;2:867-74.

3. American Diabetes Association. Economic costs of diabetes in the U.S. in 2012. Diabetes Care 2013;36:1033-46.

4. Ezzati M, Riboli E. Behavioral and dietary risk factors for noncommunicable diseases. N Engl J Med 2013;369:954-64.

5. Moodie R, Stuckler D, Monteiro C, et al. Profits and pandemics: prevention of harmful effects of tobacco, alcohol, and ultra-processed food and drink industries. Lancet 2013;38:670-9.

6. US Burden of Disease Collaborators. The State of US Health, 19902010 burden of diseases, injuries, and risk factors. JAMA 2013;310:591-608.

7. Pan XR, Li GW, Hu YH, et al. Effects of diet and exercise in preventing NIDDM in people with impaired glucose tolerance. The Da Qing IGT and Diabetes Study. Diabetes Care 1997;20:537-44.

8. Knowler WC, Barrett-Connor E, Fowler SE, et al. Reduction in the incidence of type 2 diabetes with lifestyle intervention or metformin. N Engl J Med 2002;346:393-403.

9. American Diabetes Association. Standard of Medical Care 2015. 4. Foundations of care: education, nutrition, physical activity, smoking cessation, psychosocial care, and immunization. Diabetes Care 2015;38(Suppl 1):S20-30.

10. American Diabetes Association. Standard of medical care 2015. 5. Prevention or delay of type diabetes. Diabetes Care 2015;38(Suppl 1):S31-32.

11. Moher D, Liberati A, Tetzlaff J, et al. PRISMA Group. Preferred reporting items for systematic reviews and meta-analyses: the PRISMA statement. Ann Intern Med 2009;151:264-9, W64.
12. Higgins JP, Altman DG, Gøtzsche PC, et al. The Cochrane collaboration's tool for assessing risk of bias in randomized trials. BMJ 2011;343:d5928.

13. Balshem $H$, Helfand $M$, Schunemann $H J$, et al. GRADE guidelines: 3 . Rating the quality of evidence. J Clin Epidemiol 2011;64:401-6.

14. Normand SL. Meta-analysis: formulating, evaluating, combining, and reporting. Stat Med 1999;18:321-9.

15. Deeks JJAD, Bradburn MJ. Statistical methods for examining heterogeneity and combining results from several studies in meta-analysis. In: Egger MD-SG, Altman DG, eds. Systematic reviews in health care. London: BMJ Publishing, 2001: 285-312.

16. Esposito K, Kastorini C-M, Panagiotakos DB, et al. Mediterranean diet and weight loss: meta-analysis of randomized controlled trials. Metab Syndr Relat Disord 2011;9:1-12.

17. Nordmann AJ, Suter-Zimmermann K, Bucher HC, et al. Meta-analysis comparing Mediterranean to low-fat diets for modification of cardiovascular risk factors. Am J Med 2011;124:841-51.e2.

18. Ajala O, English P, Pinkney J. Systematic review and meta-analysis of different dietary approaches to the management of type 2 diabetes. Am J Clin Nutr 2013;97:505-16.

19. Rees K, Hartley L, Flowers N, et al. 'Mediterranean' dietary pattern for the primary prevention of cardiovascular disease. Cochrane Database Syst Rev 2013;(8):CD009825.

20. Huo R, Du T, Xu Y, et al. Effects of Mediterranean-style diet on glycemic control, weight loss and cardiovascular risk factors among type 2 diabetes individuals: a meta-analysis. Eur J Clin Nutr 2014 Published Online First: 5 Nov 2014.

21. Carter P, Achana F, Troughton J, et al. A Mediterranean diet improves $\mathrm{HbA1c}$ but not fasting blood glucose compared to alternative dietary strategies: a network meta-analysis. J Hum Nutr Diet 2014;27:280-97.

22. Koloverou E, Esposito K, Giugliano D, et al. The effect of Mediterranean diet on the development of type 2 diabetes mellitus: a meta-analysis of 10 prospective studies and 136,846 participants. Metabolism 2014;63:903-11.

23. Schwingshackl L, Missbach B, König J, et al. Adherence to a Mediterranean diet and risk of diabetes: a systematic review and meta-analysis. Public Health Nutr 2015;18:1292-9.

24. Esposito K, Marfella R, Ciotola M, et al. Effect of Mediterranean-style diet on endothelial dysfunction and markers of vascular inflammation in the metabolic syndrome: a randomized trial. JAMA 2004;292:1440-6.

25. Babio N, Toledo E, Estruch R, et al. Mediterranean diets and metabolic syndrome status in the PREDIMED randomized trial. CMAJ 2014;186:E649-57.

26. Toobert DJ, Glasgow RE, Strycker LA, et al. Biologic and quality-of-life outcomes from the Mediterranean Lifestyle Program: a randomized clinical trial. Diabetes Care 2003;26:2288-93.

27. Elhayany A, Lustman A, Abel R, et al. A low carbohydrate Mediterranean diet improves cardiovascular risk factors and diabetes control among overweight patients with type 2 diabetes mellitus. A one year prospective randomized intervention study. Diabetes Obes Metab 2010;12:204-9.

28. Esposito K, Maiorino MI, Petrizzo M, et al. The effects of a Mediterranean diet on the need for diabetes drugs and remission of newly diagnosed type 2 diabetes: follow-up of a randomized trial Diabetes Care 2014;37:1824-30.

29. Salas-Salvadó J, Bulló M, Estruch R, et al. Prevention of diabetes with mediterranean diets: a subgroup analysis of a randomized trial. Ann Intern Med 2014;160:1-10.

30. Scientific Report of the 2015 Dietary Guidelines Advisory Committee. http://www.health.gov/dietaryguidelines/ 2015-scientific-report/07-chapter-2/

31. Ley SH, Hamdy O, Mohan V, et al. Prevention and management of type 2 diabetes: dietary components and nutritional strategies. Lancet 2014;383:1999-2007.

32. Esposito K, Chiodini $\mathrm{P}$, Maiorino MI, et al. Which diet for prevention of type 2 diabetes? A meta-analysis of prospective studies. Endocrine 2014;47:107-16.

33. Tonstad S, Stewart K, Oda K, et al. Vegetarian diets and incidence of diabetes in the Adventist Health Study-2. Nutr Metab Cardiovasc Dis 2013;23:292-9.

34. Willett WC, Leibel RL. Dietary fat is not a major determinant of body fat. Am J Med 2002;113(Suppl 9B):S47-59.

35. Shai I, Schwarzfuchs D, Henkin Y, et al. Weight loss with a low-carbohydrate, Mediterranean, or low-fat diet. N Engl J Med 2008;359:229-41.

36. Forouhi NG, Sharp SJ, Du H, et al. Dietary fat intake and subsequent weight change in adults: results from the European 
Prospective Investigation into Cancer and Nutrition cohorts. $\mathrm{Am} \mathrm{J}$ Clin Nutr 2009;90:1632-41.

37. Rallidis LS, Lekakis J, Kolomvotsou A, et al. Close adherence to a Mediterranean diet improves endothelial function in subjects with abdominal obesity. Am J Clin Nutr 2009;90:263-8.

38. Mente A, de Koning L, Shannon HS, et al. A systematic review of the evidence supporting a causal link between dietary factors and coronary heart disease. Arch Intern Med 2009;169:659-69.

39. Estruch R, Ros E, Salas-Salvadó J, et al. Primary prevention of cardiovascular disease with a Mediterranean diet. N Engl J Med 2013;368:1279-90.

40. Martınez-Gonzalez MA, Salas-Salvado J, Estruch R, et al. Benefits of the Mediterranean Diet: insights from the PREDIMED Study. Progress Cardiovasc Dis 2015;58:50-60.

41. Esposito K, Giugliano D. Mediterranean diet for primary prevention of cardiovascular disease. N Engl J Med 2013;369:674-5.

42. Stern MP, Williams K, Gonzalez-Villalpando C, et al. Does the metabolic syndrome improve identification of individuals at risk of type 2 diabetes and/or cardiovascular disease? Diabetes Care 2004;27:2676-81.

43. Lorenzo C, Williams K, Hunt KJ, et al. The National Cholesterol Education Program-Adult Treatment Panel III, International Diabetes Federation, and World Health Organization definitions of the metabolic syndrome as predictors of incident cardiovascular disease and diabetes. Diabetes Care 2007;30:8-13.
44. Tortosa A, Bes-Rastrollo M, Sanchez-Villegas A, et al. Mediterranean diet inversely associated with the incidence of metabolic syndrome: the SUN prospective cohort. Diabetes Care 2007:30:2957-9.

45. Rumawas ME, Dwyer JT, McKeown NM, et al. The development of the Mediterranean-style dietary pattern score and its application to the American diet in the Framingham Offspring Cohort. J Nutr 2009;139:1150-6

46. Kesse-Guyot E, Ahluwalia N, Lassale C, et al. Adherence to Mediterranean diet reduces the risk of metabolic syndrome: a 6-year prospective study. Nutr Metab Cardiovasc Dis 2013;23:677-83.

47. Calder PC, Ahluwalia N, Brouns F, et al. Dietary factors and low-grade inflammation in relation to overweight and obesity. $\mathrm{Br} J$ Nutr 2011;106(Suppl 3):S5-78.

48. Wang X, Bao W, Liu J, et al. Inflammatory markers and risk of type 2 diabetes. A systematic review and meta-analysis. Diabetes Care 2013;36:166-75.

49. Schwingshackl L, Hoffmann G. Mediterranean dietary pattern, inflammation and endothelial function: a systematic review and meta-analysis of intervention trials. Nutr Metab Cardiovasc Dis 2014:24:929-39.

50. Auchincloss AH, Diez Roux AV, Mujahid MS, et al. Neighborhood resources for physical activity and healthy foods and incidence of type 2 diabetes mellitus: the Multi-Ethnic study of Atherosclerosis. Arch Intern Med 2009;169:1698-704. 